\title{
Paternal obesity in a rodent model affects placental gene expression in a sex-specific manner
}

\author{
Natalie K Binder ${ }^{1,2}$, Sally A Beard ${ }^{2}$, Tu'uhevaha J Kaitu'u-Lino², Stephen Tong ${ }^{2}$, \\ Natalie J Hannan ${ }^{2, *}$ and David K Gardner ${ }^{1, *}$ \\ ${ }^{1}$ Department of Zoology, University of Melbourne, Parkville, Victoria 3010, Australia and \\ ${ }^{2}$ Translational Obstetrics Group, Department of Obstetrics and Gynaecology, Mercy Hospital for Women, \\ University of Melbourne, Heidelberg, Victoria 3084, Australia
}

Correspondence should be addressed to N K Binder; Email: nkbinder@unimelb.edu.au

${ }^{*}$ (N J Hannan and D K Gardner are equal senior authors)

\begin{abstract}
Fetal growth restriction (FGR) is a major obstetric complication stemming from poor placental development. We have previously demonstrated that paternal obesity in mice is associated with impaired embryo development and significantly reduced fetal and placental weights. We hypothesised that the FGR observed in our rodent model of paternal diet-induced obesity is associated with alterations in metabolic, cell signalling and stress pathways. Male C57BL/6 mice were fed either a normal or high-fat diet for 10 weeks before sperm collection for IVF and subsequent embryo transfer. On embryonic day 14, placentas were collected and RNA extracted from both male and female placentas to assess mRNA expression of 24 target genes using custom RT-qPCR arrays. Peroxisome proliferator-activated receptor alpha (Ppara) and caspase-12 (Casp12) expression were significantly altered in male placentas from obese fathers compared with normal $(\boldsymbol{P}<\mathbf{0 . 0 5})$, but not female placentas. PPARA and CASP12 proteins were localised within the placenta to trophoblast giant cells by immunohistochemistry, and relative protein abundance was determined by western blot analysis. DNA was also extracted from the same placentas to determine methylation status. Global DNA methylation was significantly increased in female placentas from obese fathers compared with normal $(P<0.05)$, but not male placentas. In this study, we demonstrate for the first time that paternal obesity is associated with changes in gene expression and methylation status of extraembryonic tissue in a sex-specific manner. These findings reinforce the negative consequences of paternal obesity before conception, and emphasise the need for more lifestyle advice for prospective fathers. Reproduction (2015) 149 435-444
\end{abstract}

\section{Introduction}

Fetal growth restriction (FGR) is a significant cause of perinatal mortality and morbidity (Bernstein et al. 2000), affecting 5-10\% of pregnancies (Neerhof 1995). FGR occurs when the fetus is unable to achieve its genetically determined potential size and in developed countries is predominantly due to placental insufficiency, reducing nutrient and oxygen supply to the developing fetus (Henriksen \& Clausen 2002). Fetal adaptation to this altered uterine milieu results in permanent changes in glucose-insulin metabolism (Hales \& Barker 2001). As such, growth-restricted individuals are at an increased risk of developing metabolic syndrome later in life, including obesity, hypertension, cardiovascular disease and type 2 diabetes (Kanaka-Gantenbein et al. 2003, Ergaz et al. 2005). The underlying aetiology of FGR from placental insufficiency is unclear.

Paternal diet-induced obesity in a mouse model has been shown to result in FGR. Fetuses from obese fathers are significantly smaller, have decreased crown-rump length and retarded limb morphology, as well as significantly smaller placentas (Binder et al. 2012a, McPherson et al. 2013). Embryos derived from obese fathers also have an increased propensity for zygote arrest, delayed preimplantation development, disproportionate changes in both pre- and post-compaction metabolism, mitochondrial dysfunction, reduced blastocyst formation, decreased cell number and aberrant cell lineage allocation to the trophectoderm (TE) or inner cell mass (ICM) (Mitchell et al. 2011, Binder et al. $2012 a, b)$. Furthermore, paternal obesity increases the likelihood of metabolic syndrome, namely obesity, in offspring (Danielzik et al. 2002, Li et al. 2009).

The paternal genome, particularly the epigenome, plays a critical role in the development and function of the placenta, which in turn regulates fetal growth (Piedrahita 2011). Genomic imprinting, an epigenetic mechanism that regulates parental allelic expression, is postulated to have evolved in response to conflict between the 
maternal and paternal genomes regarding allocation of resources to the developing fetus (Moore \& Haig 1991). Paternally expressed genes tend to enhance fetal and placental growth, while maternally expressed genes have the converse effect (Lim \& Ferguson-Smith 2010). In mice, hypermethylation in as few as one paternally expressed imprinted gene is sufficient to induce FGR (Murphy et al. 2001, McMinn et al. 2006, Dilworth et al. 2010). Additionally, global methylation changes and altered gene expression in non-imprinted genes have also been identified in FGR placentas (McCarthy et al. 2007, Einstein et al. 2010, Struwe et al. 2010).

We hypothesise that FGR as a result of paternal obesity is associated with alterations in metabolic, cell signalling and stress pathways in both the embryo and placenta. This would provide a possible mechanism underpinning the deleterious effect of male diet-induced obesity on offspring health. As such, the aim of this study was to examine gene expression, methylation and protein changes associated with FGR as a result of paternal obesity. Identifying any alterations is paramount to developing strategies to minimise or rectify the effect of paternal obesity on health of the ensuing generation.

\section{Materials and methods}

\section{Experimental animals and diets}

Six week old male C57BL/6 mice $(n=20$; all mice from Monash Animal Services, Clayton, VIC, Australia) were randomly assigned to one of the two diets for 10 weeks: control diet $(4.8 \%$ fat, meat free rat and mouse chow), or high-fat diet (22\% fat, SF00-219; Specialty Feeds, Glen Forrest, WA, Australia) manufactured to emulate a 'Western-style fast food diet'. Body weight was recorded weekly, and mice on these diets were designated as normal and obese respectively. This high-fat diet feeding regime does not affect fasting plasma glucose levels but does induce dyslipidaemia (Bakos et al. 2011, Mitchell et al. 2011, Palmer et al. 2012). Animals were maintained in a $12 \mathrm{~h}$ light: $12 \mathrm{~h}$ darkness photoperiod with food and water supplied ad libitum.

\section{Gamete collection}

Following the 10-week feeding period, male mice were killed and cauda epididymal sperm was collected and cryopreserved for IVF as described previously (Binder et al. 2012a). Control diet-fed 4-6-week-old Swiss female mice were superovulated with i.p. injections of $5 \mathrm{IU}$ pregnant mare serum gonadotrophin (Folligon, Intervet, Milton Keynes, UK) followed, $48 \mathrm{~h}$ later, by 5 IU human chorionic gonadotrophin (Chorulon, Intervet), and oocytes were collected the following morning.

\section{Mouse IVF and embryo culture}

Embryos were generated in vitro from the cryopreserved sperm of normal and obese males and fresh oocytes due to decreased fecundity with high-fat feeding (Binder et al. 2012a). Following a $4 \mathrm{~h}$ fertilisation period, pronucleate oocytes were cultured to the blastocyst stage in sequential G1/G2 media supplemented with $5 \mathrm{mg} / \mathrm{ml}$ human serum albumin under paraffin oil (Vitrolife, Goteborg, Sweden; Gardner \& Lane 2004, 2014). A humid environment of $6 \% \mathrm{CO}_{2}, 5 \% \mathrm{O}_{2}$ and $89 \% \mathrm{~N}_{2}$ at $37{ }^{\circ} \mathrm{C}$ was maintained throughout the 4-day culture with a multigas incubator (Sanyo, Osaka, Japan). Expanded and hatching blastocysts were either snap frozen or used for embryo transfer (Fig. 1). At least 100 snap-frozen blastocysts from eight IVF cultures were pooled per male mouse (four normal pooled samples and four obese pooled samples) for RNA extraction.

\section{Mouse embryo transfer}

Embryos were transferred on day 4 of culture to an asynchronous pseudopregnant female reproductive tract staged at day 3.5 of pregnancy, as described previously (Binder et al. 2012a). Briefly, pseudopregnancy was induced by mating 8-12-week-old F1 (C57BL/6 $\times \mathrm{CBA} / \mathrm{Ca})$ female mice with vasectomised F1 males. Seven pseudopregnant females received five embryos into the lumen of each uterine horn, with one horn receiving embryos derived from a normal father and the other horn receiving embryos derived from an obese father. Alternate paternal groups were transferred to both the

\begin{tabular}{|c|c|c|c|}
\hline \multicolumn{2}{|c|}{ Normal $n=10$} & \multicolumn{2}{|l|}{ Obese $n=10$} \\
\hline \multicolumn{2}{|c|}{ Eight in vitro cultures } & \multicolumn{2}{|c|}{ Seven recipient dams } \\
\hline \multirow{2}{*}{$\begin{array}{c}\text { Norm-A } n=102 \\
\text { blastocysts }\end{array}$} & \multirow{2}{*}{$\begin{array}{l}\text { Ob-A } n=219 \\
\text { blastocysts }\end{array}$} & Norm-A $n=1$ đ & Ob-A $n=1 \sigma^{\pi}$ \\
\hline & & Norm-B $n=1 \sigma^{\pi}$ & Ob-B $n=1 \sigma^{\lambda}$ \\
\hline $\begin{array}{c}\text { Norm-B } n=155 \\
\text { blastocysts }\end{array}$ & $\begin{array}{l}\text { Ob-B } n=103 \\
\text { blastocysts }\end{array}$ & Norm-C $n=1$ ठ & Ob-C $n=10^{\pi}$ \\
\hline \multirow{2}{*}{$\begin{array}{c}\text { Norm-F } n=118 \\
\text { blastocysts }\end{array}$} & \multirow{2}{*}{$\begin{array}{l}\text { Ob-F } n=117 \\
\text { blastocysts }\end{array}$} & Norm-D $n=1 \sigma^{\lambda}$ & Ob-D $n=1 \sigma^{\pi}$ \\
\hline & & Norm-E $n=10$ & Ob-E $n=1 \delta^{\lambda}$ \\
\hline \multirow{5}{*}{$\begin{array}{c}\text { Norm-G } n=104 \\
\text { blastocysts }\end{array}$} & $\begin{array}{l}\text { Ob-G } n=138 \\
\text { blastocysts }\end{array}$ & Norm-F $n=1$ 우 & Ob-F $n=1$ 웅 \\
\hline & & Norm-G $n=1$ 우 & Ob-G $n=1$ q \\
\hline & & Norm-H $n=1$ 우 & $\mathrm{Ob}-\mathrm{H} n=1$ 웅 \\
\hline & & Norm-I $n=1$ ㅇ & Ob-I $n=1$ 우 \\
\hline & & Norm-J $n=1$ 우 & Ob-J $n=1$ 우 \\
\hline mRNA extraction & & \multicolumn{2}{|c|}{$\begin{array}{c}\downarrow \\
\text { mRNA extraction } \\
\text { DNA extraction } \\
\text { Protein extraction }\end{array}$} \\
\hline
\end{tabular}

Figure 1 Experimental design flow chart. Sperm were collected from ten normal male mice and ten obese male mice. IVF was used to generate embryos. These embryos were either snap frozen in pools of at least 100 blastocysts for mRNA extraction or transferred to seven recipient dams. Five normal male and five normal female placentas and five obese male and five obese female placentas were snap frozen on E14 and divided into three wedges for mRNA, DNA and protein extraction. Norm, generated from sperm from normal male; $\mathrm{Ob}$, generated from sperm from obese male; $c$, male placenta; $q$, female placenta. 
right and left horn per recipient, to avoid any preferential uterine bias. There is no trans-uterine migration of blastocysts after embryo transfer in mice (Rulicke et al. 2006). On embryonic day 14 (E14), pregnant females were killed, fetuses were collected and sexed by examining gonadal morphology ( $\times 20$ magnification) and placentas were collected and either snap frozen or fixed in neutral buffered formalin. Five male placentas and five female placentas per paternal group (in total ten placentas generated from normal fathers and ten placentas generated from obese fathers) were selected. Each placenta was divided into three relatively equal wedges and randomly allocated for i) RNA, ii) DNA and iii) protein extraction.

\section{Custom RT-qPCR array}

Total RNA was extracted from mouse embryos and placentas using the Roche High Pure RNA Isolation Kit (Roche). Snapfrozen embryos were pooled in $200 \mu \mathrm{l} \mathrm{PBS}+400 \mu \mathrm{l}$ lysis buffer (provided with kit). Samples were incubated on ice for 2 min before being vortexed for $15 \mathrm{~s}$. For each placenta sample, $35 \mathrm{mg}$ of tissue were incubated on ice for $5 \mathrm{~min}$ in $200 \mu \mathrm{l}$ PBS $+400 \mu$ l lysis buffer before being disrupted with a rotorstator homogeniser (Bio-gen PRO200 Homogenizer, Pro Scientific, Oxford, MS, USA). RNA extraction was carried out according to the manufacturer's instructions for both sample types. Concentration and quality of eluted RNA were determined using a Nanodrop ND 1000 spectrophotometer (NanoDrop Technologies, Inc., Wilmington, DE, USA). One hundred nanograms of RNA per pooled embryo sample and 550 ng RNA/placenta sample were converted into cDNA using the Roche Transcriptor High Fidelity cDNA Synthesis Kit, according to the manufacturer's instructions. The Roche RealTime ready Configurator (http://www.realtimeready. roche.com) was used to generate Custom RealTime ready Panels in 384-well format, containing function tested, preplated qPCR assays for 24 genes of interest, three housekeeping genes, and five quality controls, in triplicate (four biological samples in triplicate per plate). The quality control assays include three positive controls to test for degradation of initial RNA and quality of cDNA synthesis, and two negative controls to control for any potential residual genomic DNA. The genes of interest were selected based on previous findings related to the effects of paternal obesity on embryo, fetal and placental development (Binder et al. 2012a,b; Table 1). Each assay well contained a gene specific primer and a Universal ProbeLibrary Probe (short FAM-labelled hydrolysis probe containing locked nucleic acid). Then, $8 \mu$ of master mix (LightCycler 480 Probes Master, Roche) and $2 \mu \mathrm{l}$ of 1:10 (embryo) or 1:20 (placenta) diluted cDNA were added to each assay well. Quantification of gene expression levels by qPCR was carried out on the LightCycler 480 Instrument (Roche), with the run conditions: $95{ }^{\circ} \mathrm{C}$ for $10 \mathrm{~min} ; 95^{\circ} \mathrm{C}$ for $10 \mathrm{~s}, 60^{\circ} \mathrm{C}$ for $30 \mathrm{~s}$ and $72{ }^{\circ} \mathrm{C}$ for $1 \mathrm{~s}$ (45 cycles; with 40 cycles chosen as the cut-off point); and $40{ }^{\circ} \mathrm{C}$ for $30 \mathrm{~s}$. The technical plate-to-plate variance using RealTime ready assays in conjunction with the LightCycler 480 Probes Master and the LightCycler 480 Instrument is negligible; inter-plate correction with a universal calibrator was not necessary. Relative quantification was determined by the comparative CT method.

\section{Immunohistochemistry}

Peroxisome proliferator-activated receptor alpha (PPARA) and CASP12 were localised by immunohistochemistry in mouse placental tissue derived from both normal $(n=10)$ and obese $(n=10)$ fathers. In brief, paraffin sections $(5 \mu \mathrm{m})$ were dewaxed in xylene and rehydrated through descending grades of ethanol (unless otherwise stated, all chemicals were obtained from Sigma-Aldrich). Sections underwent antigen retrieval using $0.01 \mathrm{~mol} / \mathrm{l}$ sodium citrate buffer $(\mathrm{pH} \mathrm{6.0)}$ for $15 \mathrm{~min}$ and then incubation in the hot buffer for a further $20 \mathrm{~min}$. Sections were washed for $5 \mathrm{~min}$ in PBS, $\mathrm{pH}$ 7.6. Following endogenous peroxidase quenching and blocking of non-specific binding, sections were incubated overnight at $4{ }^{\circ} \mathrm{C}$ with rabbit anti-PPARA (ab8934, Abcam, Cambridge, UK) at a concentration of $5 \mu \mathrm{g} / \mathrm{ml}$ in PBS or rabbit anti-caspase-12 (CASP12; ab18766, Abcam) at a concentration of $1 \mu \mathrm{g} / \mathrm{ml}$ in PBS. For isotype controls, primary antibody was substituted with rabbit lgG. Staining was visualised using the SuperPicture Kit (Invitrogen) followed by peroxidase substrate 3,3'-diaminobenzidine (DAB) (Dako, Glostrup, Denmark), and lightly counterstained with Harris hematoxylin. Sections were then dehydrated and mounted. Staining was visualised and captured using a Leica microscope and camera.

\section{Global methylation ELISA}

DNA was extracted from mouse placenta using the DNeasy Blood \& Tissue Kit (Qiagen). For each placenta sample, $35 \mathrm{mg}$ of tissue were minced before being incubated in lysis buffer for $2.5 \mathrm{~h}$ at $56^{\circ} \mathrm{C}$, with regular vortexing. DNA extraction was carried out according to the manufacturer's instructions. Concentration of eluted DNA was determined using a Nanodrop. Global methylation status was quantified using a 5-methyl-cytosine ELISA-like assay (MethylFlash Methylated DNA Quantification Kit - Colorimetric, Epigentek, Farmingdale, NY, USA). A negative control (10.0 ng unmethylated polynucleotide containing $50 \%$ cytosine), a five-point standard curve $(0.5,1.0,2.0,5.0$ and $10.0 \mathrm{ng}$ of methylated polynucleotide containing 50\% 5-methylcytosine) and $100 \mathrm{ng}$ of DNA/sample (in duplicate) were pipetted into a 96-well plate (treated to have high DNA affinity) and incubated at $37^{\circ} \mathrm{C}$ for $90 \mathrm{~min}$. The plate was then washed and capture antibody applied for $60 \mathrm{~min}$ at room temperature. Capture antibody was washed away and detection antibody added for $30 \mathrm{~min}$ at room temperature. Detection antibody was washed away and signal enhancer applied for $30 \mathrm{~min}$ at room temperature. Wells were then washed and the signal was developed. The plate was monitored away from light for up to 10 min until developed (both the standard curve wells and sample wells). Stop solution was added and the plate shaken for $1 \mathrm{~min}$ before absorbance was read at $450 \mathrm{~nm}$ on a microplate reader (xMark, Bio-Rad). Absolute quantification of the amount of methylated DNA in each sample was determined from the standard curve.

\section{Western blot}

Mouse placenta protein lysates were prepared with RIPA buffer (150 mM NaCl; $50 \mathrm{mM}$ Tris, $\mathrm{pH} 8.0 ; 1 \%$ Triton X-100; $0.5 \%$ sodium deoxychloride; $0.1 \%$ SDS; $1 \%$ protease inhibitor and 
Table 1 Genes assessed using pathway-focused RT-qPCR arrays.

\begin{tabular}{|c|c|c|}
\hline Category & Gene & Name \\
\hline \multirow[t]{5}{*}{ Paternally expressed - imprinted } & Peg10 & Paternally expressed 10 \\
\hline & Peg3 & $\begin{array}{l}\text { Paternally expressed } 3 \\
\text { gagaagcggagagatgtccaccctgggctggtggcgccgccgggcgcccggttcagtgtggggtgcactagactgcc- } \\
\text { gaccctggtcggggtgtgtgcgtagagtgctgtgctccgggagccctaccttctgatcttctatcct }\end{array}$ \\
\hline & Mest & Mesoderm specific transcript \\
\hline & Igf2 & $\begin{array}{l}\text { caccataaagagtctctgtctgtcgaatggaggtatctttcctgagacgcatcgtcctctccettctccaaaagc } \\
\text { Insulin-like growth factor } 2\end{array}$ \\
\hline & & $\begin{array}{l}\text { cgcggcttctacttcagcaggccttcaagccgtgccaaccgtcgcagccgtggcatcgtggaagagtgctgcttccg- } \\
\text { cagctgcgacctggccetcctggagacatactgtgccacccccgccaagtccgagagggacgtgtctacct }\end{array}$ \\
\hline \multirow[t]{3}{*}{ Metabolic } & Pdk4 & $\begin{array}{l}\text { Pyruvate dehydrogenase kinase, isoenzyme } 4 \\
\text { cgcttagtgaacactccttcggtgcagctggtgaagagctggtatatccagagcctgatgggatttggtggagttccatgagaa- } \\
\text { gagcccagaag }\end{array}$ \\
\hline & Ppara & Peroxisome proliferator activated receptor alpha \\
\hline & & $\begin{array}{l}\text { aactggatgacagtgacatttccctgtttgtggctgctataatttgctgtggagatcggcctggccttctaaacataggctacatt- } \\
\text { gagaagttgcaggaggggat }\end{array}$ \\
\hline \multirow[t]{10}{*}{ Cytokines and growth factors } & Tnf & Tumour necrosis factor \\
\hline & & $\begin{array}{l}\text { gggcttccagaactccaggcggtgcctatgtctcagcctcttctcattcctgcttgtggcaggggccaccacgctcttctgtc- } \\
\text { tactgaacttcggggtgatcggtccccaaagggatgagaagttccc }\end{array}$ \\
\hline & II6ra & Interleukin 6 receptor, alpha \\
\hline & & atcctctggaaccccacacaggtctctgttgaagactctgccaaccacgaggatcagtacgaaagttc \\
\hline & Prok1 & Prokineticin 1 \\
\hline & & $\begin{array}{l}\text { acccaggaagccacaagatcccettcttgaggaaacgccaacaccatacctgtccctgctcacccagcctgctgtgctc- } \\
\text { caggttcccggacggcaggtaccgctgcttccgggacttgaagaatgccaacttttagtttg }\end{array}$ \\
\hline & Cxcr4 & Chemokine (C-X-C motif) receptor 4 \\
\hline & & $\begin{array}{l}\text { tggaaccgatcagtgtgagtatatacacttctgataactactctgaagaagtgggttctggagactatgactccaacaag- } \\
\text { gaaccctgcttccgggatgaaaacgtccatttcaataggatcttcctgccc }\end{array}$ \\
\hline & Egfr & Epidermal growth factor receptor \\
\hline & & ccacctatctgcaccatcgatgtctacatgatcatggtcaagtgctggatgatagatgctgatagccgcccaaagtt \\
\hline \multirow{3}{*}{$\begin{array}{l}\text { Trophectoderm and } \\
\text { peri-implantation }\end{array}$} & Mmp2 & Matrix metalloproteinase 2 \\
\hline & Lif & $\begin{array}{l}\text { aactttgagaaggatggcaagtatggcttctgcccccatgaagccttgtttaccatgggtggca } \\
\text { Leukaemia inhibitory factor }\end{array}$ \\
\hline & LII & tgcagctcatgggtcaaatcagagagctggctagctcctctgtctcccactgtgactcact \\
\hline \multirow[t]{4}{*}{ Oxidative and ER stress } & Casp12 & Caspase 12 \\
\hline & & aaacaaacccaagattctcatcatgcaggcctgcagaggcagatataatggaactatttgggtatccaca \\
\hline & Sod1 & Superoxide dismutase 1 , soluble \\
\hline & & cgcatctcaactttcacactgcaaccgaggcgcgctgtgcaaagtcagtgacaatccgcatttccagacacagtgggt \\
\hline \multirow[t]{6}{*}{$\begin{array}{l}\text { Signalling, receptors, } \\
\text { transcription and translation }\end{array}$} & Bmpr2 & $\begin{array}{l}\text { Bone morphogenic protein receptor, type II } \\
\text { ggacatcaatcttgtgaaacaaggatgttggtctcacatcggtgatccccaagagtgcca }\end{array}$ \\
\hline & Ctnnb1 & Catenin (cadherin associated protein), beta 1 \\
\hline & & gctgaccagttccctcttcaggacagagccaatggcttggaatgagactgcagatcttggactggacatt \\
\hline & Stat3 & $\begin{array}{l}\text { Signal transducer and activator of transcription } 3 \\
\text { tggcaccttggattgagagtcaagactgggcatatgcagccagcaaagagtcacatgccacgttg }\end{array}$ \\
\hline & $\mathrm{Nr} 3 \mathrm{C} 1$ & Nuclear receptor subfamily 3 , group $C$, member 1 \\
\hline & & $\begin{array}{l}\text { caaagattgcaggtatcctatgaagagtatctctgtatgaaaaccttactgcttctctcctcagttcctaaggaaggt } \\
\text { ctgaagagccaag }\end{array}$ \\
\hline \multirow[t]{5}{*}{ Spermatogenesis } & $K d m 3 a$ & Lysine (K)-specific demethylase 3A \\
\hline & Tnn 1 & aaagctgttgtacaagaagcagtaataaaacccagactcccccagcccggaagtcagttttgacagacc \\
\hline & тाрт & $\begin{array}{l}\text { gccgcaagctaaagactcatggcatgaggagaggcaagaaccgagctcctcacaagggcgtcaagagaggtggaagcaa- } \\
\text { gagaaaataccggaagagcgtcctgaaaagtaggaaacggggcgatgatgcaagtcgcaattaccgatcc }\end{array}$ \\
\hline & Prm1 & Protamine 1 \\
\hline & & ctgggagcaggggccagtagcagcacccacgtccaccttctgtctagtaatgtccaacacctccctc \\
\hline \multirow[t]{3}{*}{ Mitochondria (nuclear encoded) } & Cox4i1 & Cytochrome $c$ oxidase subunit IV isoform 1 \\
\hline & & cgagatgaacaggggcaccaatgaatggaagacagttgtgggcatggccatgttcttcattggcttc \\
\hline & Nrf1 & $\begin{array}{l}\text { Nuclear respiratory factor } 1 \\
\text { gcagacacgtttgcttcggaaactcagagccacgttggatgagtacacgacgcgagtgggacagcaagcgattgtactctg- } \\
\text { catctcacc }\end{array}$ \\
\hline \multirow[t]{5}{*}{ Housekeeping } & Hprt & Hypoxanthine guanine phosphoribosyl transferase \\
\hline & & $\begin{array}{l}\text { ggagcggtagcacctcctccgccggcttcctcctcagaccgcttttgccgcgagccgaccggtcccgtcatgccgacccg- } \\
\text { cagtccaagcgtcgtgattagcgatgatgaaccag }\end{array}$ \\
\hline & Tbp & TATA box binding protein \\
\hline & & $\begin{array}{l}\text { ggggagctgtgatgtgaagttccctataaggctggaaggccttgtgctgacccaccagcagttcagtagctatgagccagaat- } \\
\text { tatttcctgg }\end{array}$ \\
\hline & $B 2 m$ & $\begin{array}{l}\text { Beta-2 microglobulin } \\
\text { tacgcctgcagagttaagcatgccagtatggccgagcccaagaccgtctactgggatcgagacatgtgatcaagcatcat- } \\
\text { gatgctctgaagattcatttgaacc }\end{array}$ \\
\hline
\end{tabular}


$1 \%$ phenylmethylsulphonyl fluoride). Briefly, $25 \mathrm{mg}$ of each placental sample were homogenised in $600 \mu \mathrm{l}$ RIPA buffer before being rotated at $4{ }^{\circ} \mathrm{C}$ for $2 \mathrm{~h}$. Lysates were then centrifuged at $12000 \mathrm{~g}$ for $20 \mathrm{~min}$ at $4{ }^{\circ} \mathrm{C}$ and the supernatant transferred to a new tube. Total protein was quantitated in each sample using a colorimetric bicinchoninic acid protein assay (Pierce BCA Protein Assay Kit, Thermo Scientific, Waltham, MA, USA). Thirty micrograms of placental lysate per sample were separated on $12 \%$ polyacrylamide gels and were then transferred onto PVDF membranes (Millipore, Billerica, MA, USA). Membranes were blocked overnight in 1\% BSA TBS before overnight incubation with rabbit anti-PPARA (ab8934, Abcam, 1:1000 dilution) or rabbit anti-CASP12 (ab18766, Abcam, 1:200 dilution). Membranes were subsequently stripped and blocked with 5\% skim milk TBS for $1 \mathrm{~h}$ before overnight incubation with rabbit antiGAPDH (3683S, Cell Signalling Technology, Danvers, MA, USA, 1:10 000 dilution). Bands were visualised using a chemiluminescence detection system (GE Healthcare Life Sciences, Little Chalfont, UK) and ChemiDoc XRS (Bio-Rad). GAPDH was used as a protein loading control. Relative densitometry was determined using the QuantityOne Software (Bio-Rad).

\section{Statistical analysis}

After testing the distribution of data with the D'Agostino-Pearson omnibus normality test, statistical analysis was performed on raw data. Mouse weight and body fat composition were normally distributed and statistically analysed using a parametric t-test. Implantation and ongoing pregnancy rate were statistically analysed using a contingency table and Fisher's exact test. Fetal outcomes including fetal and placental weights, crown-rump length and sex ratio were not normally distributed and statistically analysed non-parametrically using the MannWhitney $U$ test. Relative protein abundance by densitometry was not normally distributed and statistically analysed nonparametrically using the Mann-Whitney $U$ test. Global DNA methylation was not normally distributed and statistically analysed non-parametrically using the Mann-Whitney $U$ test. For qPCR array data, each gene detectable below the limit of detection (cycle 40) was analysed individually, without assuming a consistent S.D. and correction for multiple comparisons using the Holm-Sidak method. Statistical analysis was performed using PRISM version 6.00 for Windows (GraphPad, San Diego, CA, USA). $P$ values $<0.05$ were considered statistically significant.

Furthermore, univariate general linear modelling was performed with paternal phenotype (normal or obese) as a fixed factor and recipient dam, transfer horn, implantation rate, fetal number per horn, transfer date (season), fetal weight and placental weight as covariates. Despite mice being housed in a constant light/darkness cycle, seasonality had a confounding effect on the data. As such, all fetal and placental samples used in the present study were generated within a 6-week period to avoid any seasonal effect.

\section{Animal ethics}

This study was carried out in strict accordance with the Australian code of practice for the care and use of animals for scientific purposes. Ethical approval was obtained from the University of Melbourne Animal Ethics Committee (\#1011628.1) before experimentation.

\section{Results}

\section{Dietary effects on weight gain and fat deposits}

Male C57BL/6 mice fed the high-fat diet for 10 weeks (obese) gained significantly more weight than mice fed the control diet (normal) $(19.9 \pm 1.5 \mathrm{~g}$ vs $12.8 \pm 0.8 \mathrm{~g}$ respectively; $P<0.01)$. Importantly, the obese mice were significantly heavier at the time of sperm collection than the normal mice $(36.4 \pm 1.5 \mathrm{~g}$ vs $29.4 \pm 0.8 \mathrm{~g}$ respectively; $P<0.01)$. Obese mice also had significantly increased peritoneal fat deposits compared with normal mice, which did not normalise with weight $(6.0 \pm 0.2 \%$ vs $2.8 \pm 0.4 \%$ respectively; $P<0.001)$. Similar changes to body composition with high-fat feeding in this mouse strain have been reported previously (Binder et al. 2012a,b).

\section{Obesity effects on blastocyst gene expression}

Twenty-four target genes involved in metabolic, cell signalling and stress pathways were selected based on our observations of the effect of paternal obesity on embryo and fetal/placental development, including altered preimplantation metabolism, delayed cell cycle kinetics and FGR. In blastocysts, Peg10, Mest, Igf2, I/6ra, Lif, Sod1, Bmpr2, Ctnnb1, Stat3, Kdm3a, Cox4i1 and Nrf1 had detectable levels of mRNA present (Fig. 2). Of these, Cox4i1 mRNA was increased in blastocysts

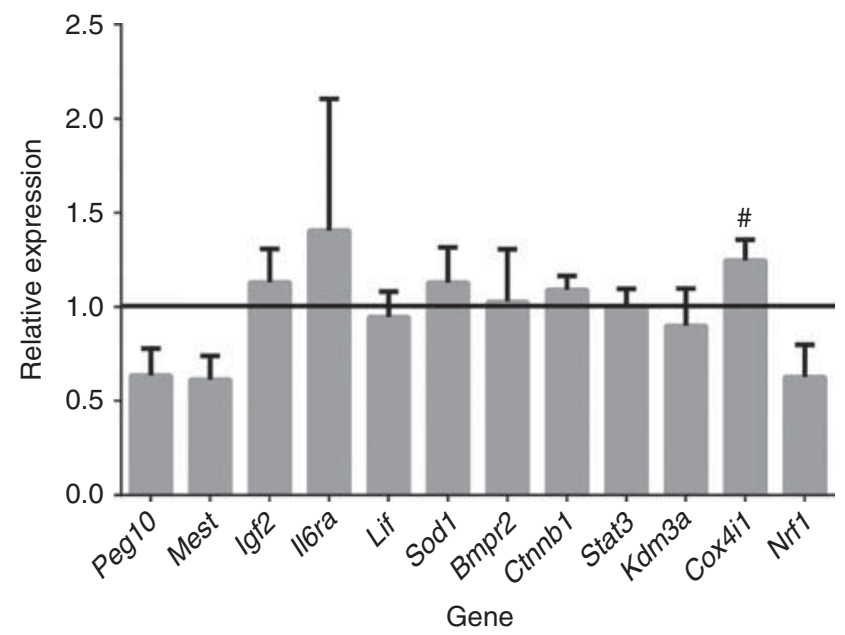

Figure 2 The expression of Cox4i1 tended to be higher in mouse blastocysts derived from obese fathers. Graphical representation of 12 genes (24 investigated) with detectable levels of mRNA in blastocysts derived from normal and obese fathers. The dark horizontal line represents relative gene expression in blastocysts derived from normal fathers and light bars represent relative gene expression in blastocysts derived from obese fathers. Data are expressed as mean \pm s.E.M., normalised to normal. ${ }^{\#} P=0.056, n=4$ pools of 102-219 blastocysts/sample per paternal group. 
Table 2 Pregnancy outcomes of transfer of embryos generated from the sperm of normal and obese males into pseudopregnant recipient female mice.

\begin{tabular}{lccc}
\hline Parameter & Normal & Obese & P value \\
\hline Implantation (\%) & 79.00 & 67.29 & $<0.01$ \\
Fetuses (as \% of transferred & 54.00 & 43.93 & $<0.05$ \\
$\quad$ embryos) & & & \\
Fetal weight (mg) & $131.91 \pm 3.38$ & $122.16 \pm 3.30$ & $<0.05$ \\
Placental weight (mg) & $139.67 \pm 4.48$ & $125.49 \pm 4.44$ & $<0.05$ \\
Fetal/placental ratio & $0.98 \pm 0.03$ & $1.02 \pm 0.04$ & $\mathrm{NS}$ \\
Crown-rump length (mm) & $10.25 \pm 0.11$ & $9.86 \pm 0.11$ & $<0.01$ \\
\hline
\end{tabular}

Data are expressed as mean \pm s.E.M., except for percentage data. $n=100$ embryos transferred/paternal group (from which placentas were collected for RNA, DNA and protein extraction); NS, not significant.

derived from obese fathers compared with those derived from normal fathers, although this was of borderline significance $(P=0.056)$.

\section{Paternal obesity effects on fetal and placental weight}

Embryos derived from the sperm of obese males had a reduced ability to implant into the uterine wall of a recipient female following blastocyst transfer, resulting in fewer viable fetuses (Table 2). Paternal obesity did not affect the fetal sex ratio at E14 (Fig. 3). Fetal and placental weights were significantly reduced in conceptuses of obese males compared with normal and their crown-rump lengths were shorter (Table 2). Both male and female placentas derived from obese fathers weighed on average $10.2 \%$ less than those derived from normal fathers. Paternal obesity was also associated with a fourfold higher rate of fetal growth below the 10th centile compared with normal $(15.7 \%$ vs $3.7 \%$ respectively; $P<0.001)$.

\section{Sex-specific obesity effects on placental gene expression}

Expression of Cxcr4 was significantly reduced in placentas derived from obese fathers (Fig. 4A); however, this significance was no longer observed when male and female placentas were assessed separately. In male placentas only, paternal obesity was associated with significantly decreased expression of Ppara and Casp12 $(P<0.05)$, and reduced expression of Tnf and Mmp2 $(P<0.1)$ (Fig. 4B). No significant changes in gene expression were observed in female placentas derived from obese fathers (Fig. 4C).

\section{Sex-specific obesity effects on placental DNA methylation}

While no changes were observed in the expression of imprinted genes Peg10, Peg3, Mest and Igf2, epigenetic modification across the genome might contribute to the FGR observed with paternal obesity. Global DNA methylation was detected with a 5-methyl-cytosine antibody in an ELISA-like approach. Paternal obesity did not affect global DNA methylation when no distinction was made between male and female placentas (Fig. 5A). However, taking sex into consideration, in female placentas only, paternal obesity was associated with significantly increased global DNA methylation (Fig. 5C). There was no change in global DNA methylation status in male placentas (Fig. 5B).

\section{Obesity effects on PPARA and CASP12 placental protein}

In the placenta, both PPARA and CASP12 strongly localised to the junctional zone and trophoblast giant cells, with CASP12 showing distinct peri-nuclear staining (Fig. 6A, B, D and E respectively). PPARA was also observed in peri-vascular cells in some placental vessels (Fig. 6C). PPARA protein abundance in male (Fig. 6G) and female placentas and CASP12 protein abundance (both pro and cleavage forms) in male and female placentas were not affected by paternal obesity (data not shown).

\section{Discussion}

While a negative effect of male obesity on reproductive health is now more widely recognised, the underlying mechanisms resulting in reduced fecundity and subsequent FGR are yet to be fully elucidated. The data from this study demonstrate for the first time that paternal obesity is associated with changes in placental gene expression and global DNA methylation in a sex-specific manner.

In the current study, genomic analysis identified a tendency for increased levels $(P=0.056)$ of cytochrome $C$ oxidase subunit IV isoform 1 (Cox4i1) mRNA in

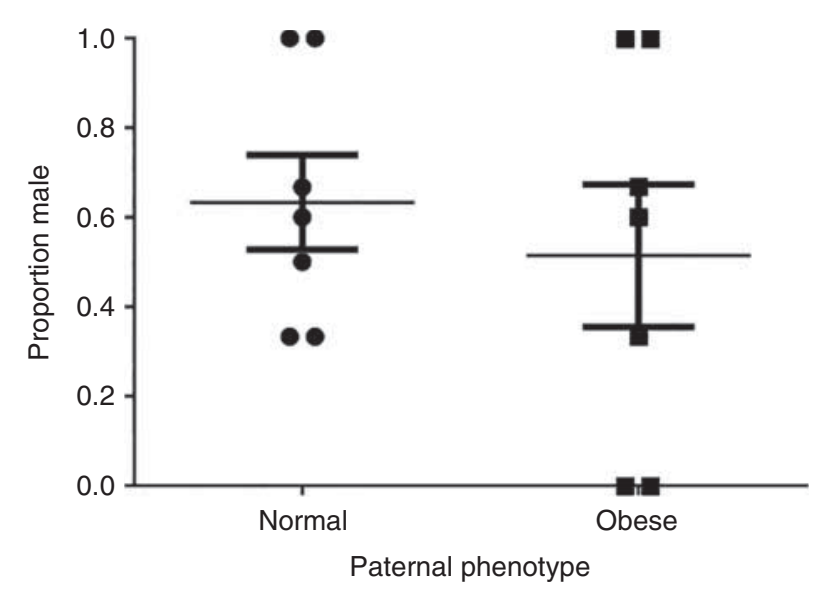

Figure 3 Mouse fetal sex ratio was not affected by paternal obesity. The graph depicts the proportion of male fetuses present at E14 following embryo transfer. Each data-point represents the sex ratio determined per individual recipient female. Horizontal lines represent the mean \pm S.E.M., $n=7$ recipient females/paternal group. 

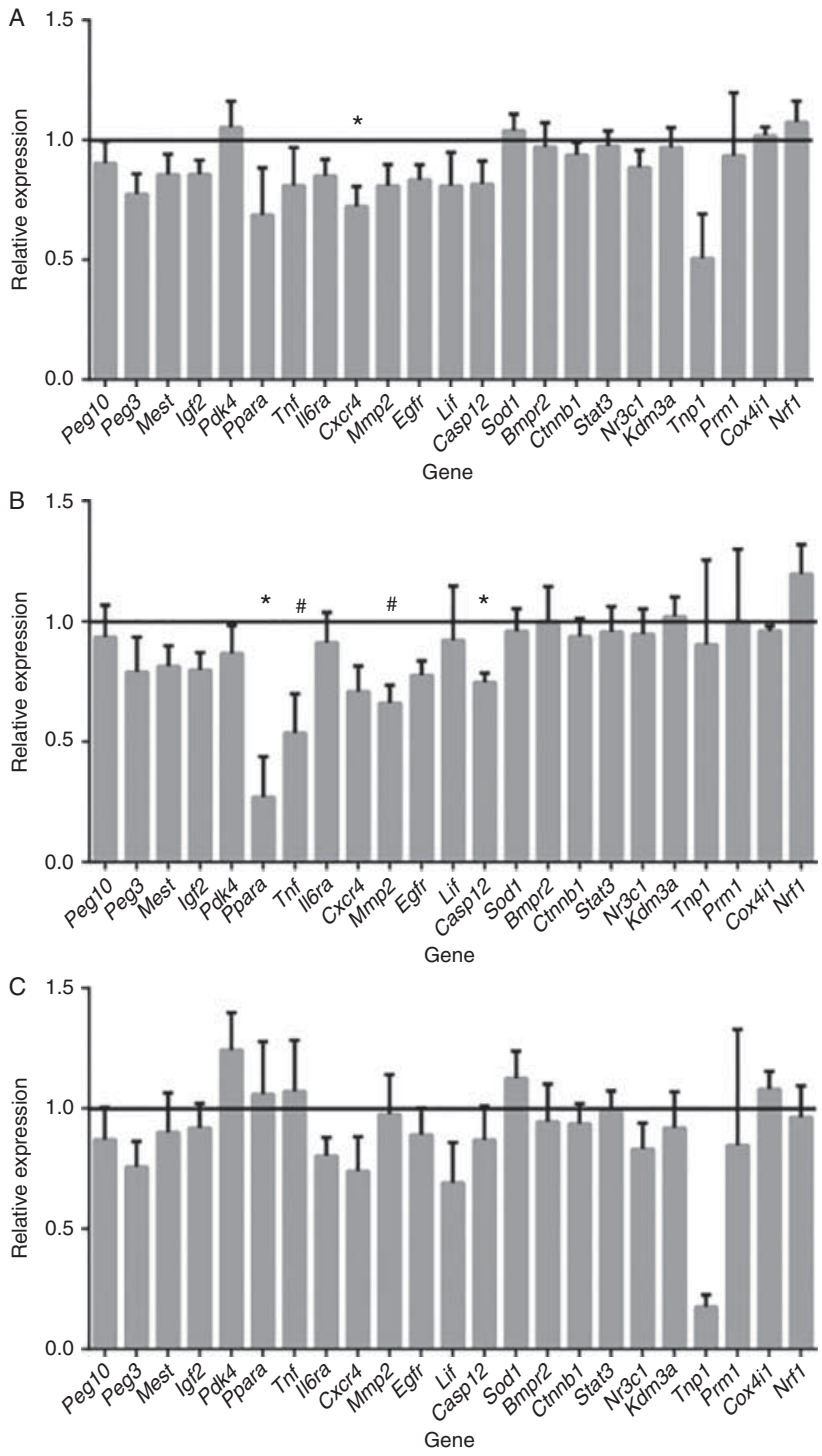

Figure 4 The expression of Ppara and Casp12 were significantly downregulated in mouse male placenta derived from obese fathers. The graph depicts 23 genes (of 24 investigated) with detectable levels of mRNA in total placentas (A), male placentas (B) and female placentas (C) derived from normal and obese fathers. The dark horizontal line represents relative gene expression in placentas derived from normal fathers and light bars represent relative gene expression in placentas derived from obese fathers. Data are expressed as mean \pm S.E.M. normalised to normal. ${ }^{*} P<0.05,{ }^{\sharp} P<0.1, n=5$ male and five female placentas (ten total placentas)/paternal group.

blastocysts derived from obese fathers compared with normal. Nuclear encoded Cox4i1 localises to the inner mitochondria membrane and forms part of the electron transport chain (Blake et al. 2014). Dysregulation of Cox4i1 affects mitochondrial membrane potential (Miceli et al. 2012); this finding is consistent with our previous report of altered pre-compaction mitochondrial metabolism with paternal obesity (Binder et al. 2012a). Importantly, we also identified significantly increased levels of Cox4i1 mRNA in spermatozoa from obese males (Binder et al. 2015), and the increased Cox4i1 mRNA in the blastocyst may be direct carryover from the spermatozoa. This provides further evidence that mRNA present in the spermatozoa likely has a functional role in early embryonic development (Hosken \& Hodgson 2014). Recently, it has been established that a paternal load of RNA is selectively delivered into the oocyte by the fertilising sperm, and this RNA is translated in the zygote,
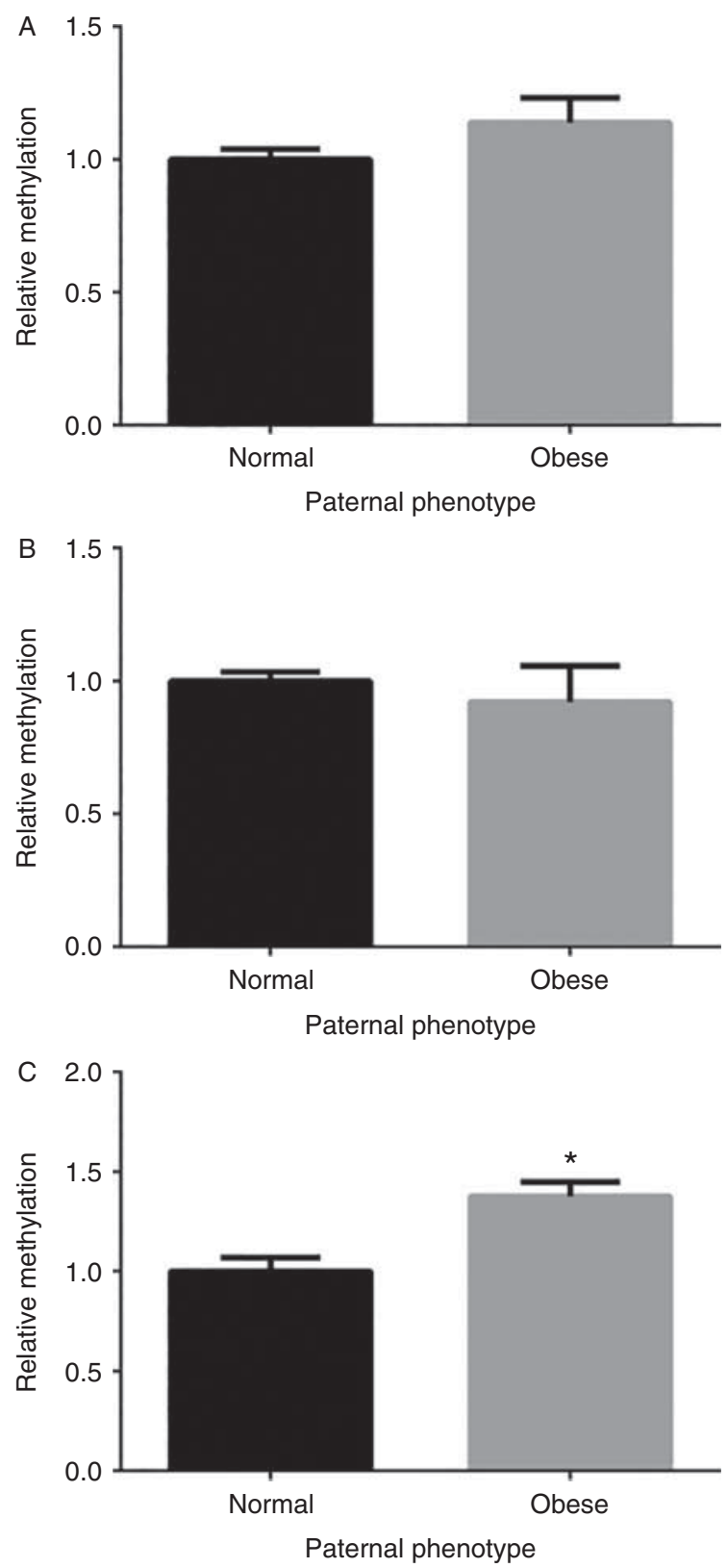

Figure 5 Global DNA methylation of mouse female placenta was significantly increased with paternal obesity. The dark and light bars represent relative global DNA methylation in total placentas (A), male placentas (B) and female placentas (C) derived from normal and obese fathers respectively. Data are expressed as mean \pm s.E.M. $* P<0.05, n=5$ male and five female placentas (ten total placentas)/paternal group. 

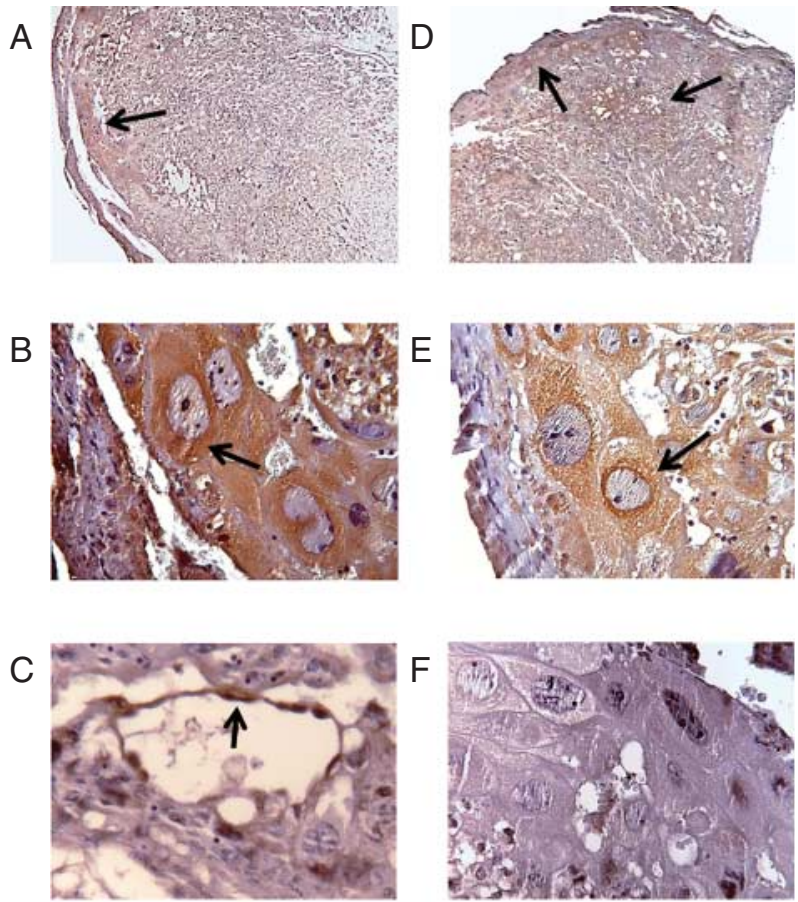

G

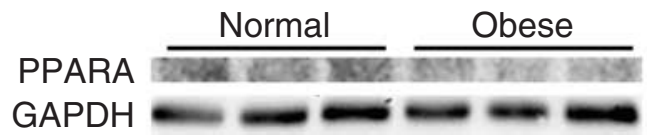

Figure 6 PPARA and CASP12 localise strongly to the junctional zone trophoblast giant cells in the mouse placenta. Immunolocalisation of PPARA (A, B and C) and CASP12 (D and E) in placental tissue from E14 mice. PPARA localises to trophoblast giant cells (B) and some vessels (C), and CASP12 localises to trophoblast giant cells, with distinct peri-nuclear staining (E). This staining is not present in the negative control (F). A and D: $\times 100$ magnification and B, C, E and F: $\times 250$ magnification. Arrows indicate areas of staining. PPARA protein (52 kDa) abundance decreased modestly in male mouse placentas derived from obese fathers compared with those from normal fathers (representative image of western blot probed with a PPARA antibody, normalised to the GAPDH loading control (G), $n=5$ male placentas/paternal group).

having a direct role in early embryogenesis. Work in model organism Caenorhabditis elegans has identified hundreds of paternally derived mRNA present in the 1 -cell embryo, before initiation of transcription (Stoeckius et al. 2014).

We have previously shown that paternal obesity is associated with significantly altered cell lineage allocation in the blastocyst, resulting in a decreased ICM to TE ratio (Binder et al. 2012a). Having fewer ICM cells can contribute to observed differences in blastocyst gene expression due to the unique expression profiles of the ICM and TE (Guo et al. 2010). However, in vitro culture as performed in this study is known to diminish the differential expression of genes between the two cell lineages (Giritharan et al. 2012), meaning that a reduced ICM:TE is unlikely to affect gene expression in this instance.
Ppara expression was significantly downregulated in male placentas derived from obese fathers. PPARA is a nuclear transcription factor belonging to the steroid hormone receptor superfamily, targeting genes involved in cell proliferation and inflammation responses. PPARA is the transcriptional master regulator of lipid metabolism (Jump 2008) and can function to protect cells against reactive oxygen species (ROS)-induced apoptosis (Ashibe \& Motojima 2009, Tang et al. 2014). Inhibition of PPARA induces apoptosis and cellular damage, and the reduced Ppara expression observed in male placentas derived from obese fathers may lead to increased cellular damage (Tang et al. 2014). Resveratrol, a polyphenol found in a number of plants protects against ROS-induced apoptosis by upregulating Ppara expression (Qin et al. 2014). Interestingly, resveratrol has been suggested as a therapeutic to improve fetal outcomes and growth trajectories in pregnancies complicated by FGR (Poudel et al. 2013), and resveratrol administration postnatally may protect against dietinduced metabolic syndrome in FGR offspring (Dolinsky et al. 2011, Rueda-Clausen et al. 2012).

Casp12 expression was also significantly downregulated in male placentas derived from obese fathers; however, this same effect was not translated to relative protein abundance of either the pro- or cleavage form. In rodents, Casp12 mediates apoptosis in response to endoplasmic reticulum stress. Decreased Casp12 expression might suggest that ROS-induced apoptosis due to downregulation of Ppara is a caspase-independent process (Martinvalet et al. 2005).

Several paternally expressed, imprinted genes (Peg10, Peg3, Mest and Igf2) were investigated, with no significant change induced by paternal obesity. Global DNA methylation was, however, significantly higher in female placentas derived from obese fathers compared with normal. In FGR placentas, there have been reports of altered methylation patterns of non-imprinted genes (Einstein et al. 2010), as well as altered expression of imprinted genes without altered methylation patterns (Diplas et al. 2009). Paternally expressed genes tend to enhance fetal and placental growth, while maternally expressed genes have the converse effect (Lim \& Ferguson-Smith 2010), and as such, hypermethylation of paternally expressed genes may result in FGR. Placental hypermethylation has also been linked to other complications of pregnancy including preeclampsia and placental mesenchymal dysplasia, both of which are associated with increased rates of FGR and fetal death (Anton et al. 2014, Chen et al. 2014, Liu et al. 2014). Interestingly, a rodent model of gestational diabetes has shown overlap between differentially methylated genes in the placenta and fetal tissues, which affect metabolic pathways (Petropoulos et al. 2015). The effect of paternal obesity on fetal methylation status also warrants attention.

Fetal sex ratio was not affected by paternal obesity; however, the population was skewed toward males 
(median proportion of males for both paternal groups $=0.60$ ), as is common in IVF cohorts (Maalouf et al. 2014). Both gene expression and global DNA methylation showed sex-specific alterations in FGR placentas. There are known sex-specific differences in fetal growth, mortality and morbidity (Stevenson et al. 2000, Di Renzo et al. 2007, Engel et al. 2008), and males experience significantly poorer outcomes in pregnancies complicated by preeclampsia, preterm delivery and FGR (Vatten \& Skjaerven 2004). It has been suggested that male and female fetuses employ different mechanisms to deal with an adverse in utero environment, such as the one caused by placental insufficiency, to try and maintain their growth trajectories (for review, see Clifton (2010)).

In conclusion, this is the first study to identify differences in both embryonic and placental gene expressions as a result of paternal diet-induced obesity. Paternal obesity also affects placentas in a sex-specific manner at the molecular level. Studies expanding on the genomic and epigenomic analysis of both male and female placentas as well as the maternal and fetal components of the placenta will likely yield significant insights into the mechanism underlying the deleterious effect of paternal obesity on the ensuing generation.

\section{Declaration of interest}

The authors declare that there is no conflict of interest that could be perceived as prejudicing the impartiality of the research reported.

\section{Funding}

This work was supported by the University of Melbourne (to D K Gardner), the National Health and Medical Research Council (\#1050765 to S Tong, \#1062418 to T J Kaitu'u-Lino and \#628927 to $\mathrm{N} \mathrm{J} \mathrm{Hannan),} \mathrm{the} \mathrm{Australian} \mathrm{Postgraduate}$ Award (to N K Binder) and the Jasper Loftus-Hills Memorial Award (to N K Binder).

\section{Acknowledgements}

The authors acknowledge Dr Louise Zieseniss for technical support and assistance.

\section{References}

Anton L, Brown AG, Bartolomei MS \& Elovitz MA 2014 Differential methylation of genes associated with cell adhesion in preeclamptic placentas. PLoS ONE 9 e100148. (doi:10.1371/journal.pone.0100148)

Ashibe B \& Motojima K 2009 Fatty aldehyde dehydrogenase is up-regulated by polyunsaturated fatty acid via peroxisome proliferator-activated receptor $\alpha$ and suppresses polyunsaturated fatty acid-induced endoplasmic reticulum stress. FEBS Journal 276 6956-6970. (doi:10.1111/j.17424658.2009.07404.x)

Bakos HW, Mitchell M, Setchell BP \& Lane M 2011 The effect of paternal diet-induced obesity on sperm function and fertilization in a mouse model. International Journal of Andrology 34 402-410. (doi:10.1111/ j.1365-2605.2010.01092.x)
Bernstein IM, Horbar JD, Badger GJ, Ohlsson A \& Golan A 2000 Morbidity and mortality among very-low-birth-weight neonates with intrauterine growth restriction. The Vermont Oxford Network. American Journal of Obstetrics and Gynecology 182 198-206. (doi:10.1016/S00029378(00)70513-8)

Binder NK, Hannan NJ \& Gardner DK 2012a Paternal diet-induced obesity retards early mouse embryo development, mitochondrial activity and pregnancy health. PLOS ONE 7 e52304. (doi:10.1371/journal.pone. 0052304)

Binder NK, Mitchell M \& Gardner DK 2012 b Parental diet-induced obesity leads to retarded early mouse embryo development and altered carbohydrate utilisation by the blastocyst. Reproduction, Fertility, and Development 24 804-812. (doi:10.1071/RD11256)

Binder NK, Sheedy JR, Hannan NJ \& Gardner DK 2015 Male obesity is associated with changed spermatozoa Cox4i1 mRNA level and altered seminal vesicle fluid composition in a mouse model. Molecular Human Reproduction In Press. (doi:10.1093/molehr/gav010)

Blake JA, Bult CJ, Eppig JT, Kadin JA, Richardson JE \& Mouse Genome Database G 2014 The Mouse Genome Database: integration of and access to knowledge about the laboratory mouse. Nucleic Acids Research 42 D810-D817. (doi:10.1093/nar/gkt1225)

Chen CP, Su YN, Lin MH, Wang TY, Chern SR, Kuo YL, Chen YT \& Wang W 2014 Detection of altered methylation status at 11 p15.5 and $7 q 32$ in placental mesenchymal dysplasia. Taiwanese Journal of Obstetrics \& Gynecology 53 68-73. (doi:10.1016/j.tjog.2013.10.036)

Clifton VL 2010 Review: Sex and the human placenta: mediating differential strategies of fetal growth and survival. Placenta 31 (Suppl) S33-S39. (doi:10.1016/j.placenta.2009.11.010)

Danielzik S, Langnase K, Mast M, Spethmann C \& Muller MJ 2002 Impact of parental BMI on the manifestation of overweight 5-7 year old children. European Journal of Nutrition 41 132-138. (doi:10.1007/s00394-0020367-1)

Dilworth MR, Kusinski LC, Cowley E, Ward BS, Husain SM, Constancia M, Sibley CP \& Glazier JD 2010 Placental-specific Igf2 knockout mice exhibit hypocalcemia and adaptive changes in placental calcium transport. PNAS 107 3894-3899. (doi:10.1073/pnas. 0911710107)

Diplas AI, Lambertini L, Lee MJ, Sperling R, Lee YL, Wetmur J \& Chen J 2009 Differential expression of imprinted genes in normal and IUGR human placentas. Epigenetics 4 235-240. (doi:10.4161/epi.9019)

Di Renzo GC, Rosati A, Sarti RD, Cruciani L \& Cutuli AM 2007 Does fetal sex affect pregnancy outcome? Gender Medicine 4 19-30. (doi:10.1016/ S1550-8579(07)80004-0)

Dolinsky VW, Rueda-Clausen CF, Morton JS, Davidge ST \& Dyck JR 2011 Continued postnatal administration of resveratrol prevents diet-induced metabolic syndrome in rat offspring born growth restricted. Diabetes 60 2274-2284. (doi:10.2337/db11-0374)

Einstein F, Thompson RF, Bhagat TD, Fazzari MJ, Verma A, Barzilai N \& Greally JM 2010 Cytosine methylation dysregulation in neonates following intrauterine growth restriction. PLOS ONE 5 e8887. (doi:10. 1371/journal.pone.0008887)

Engel PJ, Smith R, Brinsmead MW, Bowe SJ \& Clifton VL 2008 Male sex and pre-existing diabetes are independent risk factors for stillbirth. Australian \& New Zealand Journal of Obstetrics \& Gynaecology 48 375-383. (doi:10.1111/j.1479-828X.2008.00863.x)

Ergaz Z, Avgil M \& Ornoy A 2005 Intrauterine growth restriction-etiology and consequences: what do we know about the human situation and experimental animal models? Reproductive Toxicology 20 301-322. (doi:10.1016/j.reprotox.2005.04.007)

Gardner DK \& Lane M 2004 Culture of the mammalian preimplantation embryo. In A Laboratory Guide to the Mammalian Embryo, ch 3 pp 41-61. Eds DK Gardner, M Lane \& A Watson. Oxford: Oxford University Press.

Gardner DK \& Lane M 2014 Mammalian preimplantation embryo culture. Methods in Molecular Biology 1092 167-182. (doi:10.1007/978-160327-292-6_11)

Giritharan G, Delle Piane L, Donjacour A, Esteban FJ, Horcajadas JA, Maltepe E \& Rinaudo P 2012 In vitro culture of mouse embryos reduces differential gene expression between inner cell mass and trophectoderm. Reproductive Sciences 19 243-252. (doi:10.1177/ 1933719111428522) 
Guo G, Huss M, Tong GQ, Wang C, Li Sun L, Clarke ND \& Robson P 2010 Resolution of cell fate decisions revealed by single-cell gene expression analysis from zygote to blastocyst. Developmental Cell 18 675-685. (doi:10.1016/j.devcel.2010.02.012)

Hales CN \& Barker DJ 2001 The thrifty phenotype hypothesis. British Medical Bulletin 60 5-20. (doi:10.1093/bmb/60.1.5)

Henriksen T \& Clausen T 2002 The fetal origins hypothesis: placental insufficiency and inheritance versus maternal malnutrition in wellnourished populations. Acta Obstetricia et Gynecologica Scandinavica 81 112-114. (doi:10.1034/j.1600-0412.2002.810204.x)

Hosken DJ \& Hodgson DJ 2014 Why do sperm carry RNA? Relatedness, conflict, and control Trends in Ecology \& Evolution 29 451-455. (doi:10. 1016/j.tree.2014.05.006)

Jump DB $2008 \mathrm{~N}-3$ polyunsaturated fatty acid regulation of hepatic gene transcription. Current Opinion in Lipidology 19 242-247. (doi:10.1097/ MOL.0b013e3282ffaf6a)

Kanaka-Gantenbein C, Mastorakos G \& Chrousos GP 2003 Endocrinerelated causes and consequences of intrauterine growth retardation. Annals of the New York Academy of Sciences 997 150-157. (doi:10. 1196/annals.1290.017)

Li L, Law C, Lo Conte R \& Power C 2009 Intergenerational influences on childhood body mass index: the effect of parental body mass index trajectories. American Journal of Clinical Nutrition 89 551-557. (doi:10. 3945/ajcn.2008.26759)

Lim AL \& Ferguson-Smith AC 2010 Genomic imprinting effects in a compromised in utero environment: implications for a healthy pregnancy. Seminars in Cell \& Developmental Biology 21 201-208. (doi:10.1016/j.semcdb.2009.10.008)

Liu H, Tang Y, Liu X, Zhou Q, Xiao X, Lan F, Li X, Hu R, Xiong Y \& Peng T 2014 14-3-3 tau (YWHAQ) gene promoter hypermethylation in human placenta of preeclampsia. Placenta 35 981-988. (doi:10.1016/j. placenta.2014.09.016)

Maalouf WE, Mincheva MN, Campbell BK \& Hardy IC 2014 Effects of assisted reproductive technologies on human sex ratio at birth. Fertility and Sterility 101 1321-1325. (doi:10.1016/j.fertnstert.2014.01.041)

Martinvalet D, Zhu P \& Lieberman J 2005 Granzyme A induces caspaseindependent mitochondrial damage, a required first step for apoptosis. Immunity 22 355-370. (doi:10.1016/j.immuni.2005.02.004)

McCarthy C, Cotter FE, McElwaine S, Twomey A, Mooney EE, Ryan F \& Vaughan J 2007 Altered gene expression patterns in intrauterine growth restriction: potential role of hypoxia. American Journal of Obstetrics and Gynecology 196 70.e1-70.e6. (doi:10.1016/j.ajog.2006.08.027)

McMinn J, Wei M, Schupf N, Cusmai J, Johnson EB, Smith AC, Weksberg R, Thaker HM \& Tycko B 2006 Unbalanced placental expression of imprinted genes in human intrauterine growth restriction. Placenta $\mathbf{2 7}$ 540-549. (doi:10.1016/j.placenta.2005.07.004)

McPherson NO, Bakos HW, Owens JA, Setchell BP \& Lane M 2013 Improving metabolic health in obese male mice via diet and exercise restores embryo development and fetal growth. PLOS ONE 8 e71459. (doi:10.1371/journal.pone.0071459)

Miceli MV, Jiang JC, Tiwari A, Rodriguez-Quiñones JF \& Jazwinski SM 2012 Loss of mitochondrial membrane potential triggers the retrograde response extending yeast replicative lifespan. Frontiers in Genetics 2 102. (doi:10.3389/fgene.2011.00102)

Mitchell M, Bakos HW \& Lane M 2011 Paternal diet-induced obesity impairs embryo development and implantation in the mouse. Fertility and Sterility 95 1349-1353. (doi:10.1016/j.fertnstert.2010.09. 038)

Moore T \& Haig D 1991 Genomic imprinting in mammalian development: a parental tug-of-war. Trends in Genetics 7 45-49. (doi:10.1016/01689525(91)90040-W)
Murphy SK, Wylie AA \& Jirtle RL 2001 Imprinting of PEG3, the human homologue of a mouse gene involved in nurturing behavior. Genomics 71 110-117. (doi:10.1006/geno.2000.6419)

Neerhof MG 1995 Causes of intrauterine growth restriction. Clinics in Perinatology 22 375-385.

Palmer NO, Bakos HW, Owens JA, Setchell BP \& Lane M 2012 Diet and exercise in an obese mouse fed a high-fat diet improve metabolic health and reverse perturbed sperm function. American Journal of Physiology. Endocrinology and Metabolism 302 E768-E780. (doi:10.1152/ajpendo. 00401.2011)

Petropoulos S, Guillemin C, Ergaz Z, Dimov S, Suderman M, WeinsteinFudim L, Ornoy A \& Szyf M 2015 Gestational diabetes alters offspring DNA methylation profiles in human and rat: identification of key pathways involved in endocrine system disorders, insulin signaling, diabetes signaling and IL-K signaling. Endocrinology In press. (doi:10. 1210/en.2014-1643)

Piedrahita JA 2011 The role of imprinted genes in fetal growth abnormalities. Birth Defects Research. Part A, Clinical and Molecular Teratology 91 682-692. (doi:10.1002/bdra.20795)

Poudel R, Stanley JL, Rueda-Clausen CF, Andersson IJ, Sibley CP, Davidge ST \& Baker PN 2013 Effects of resveratrol in pregnancy using murine models with reduced blood supply to the uterus. PLOS ONE $\mathbf{8}$ e64401. (doi:10.1371/journal.pone.0064401)

Qin S, Lu Y \& Rodrigues GA 2014 Resveratrol protects RPE cells from sodium iodate by modulating PPAR $\alpha$ and PPAR $\delta$. Experimental Eye Research 118 100-108. (doi:10.1016/j.exer.2013.11.010)

Rueda-Clausen CF, Morton JS, Dolinsky VW, Dyck JR \& Davidge ST 2012 Synergistic effects of prenatal hypoxia and postnatal high-fat diet in the development of cardiovascular pathology in young rats. American Journal of Physiology. Regulatory, Integrative and Comparative Physiology 303 R418-R426. (doi:10.1152/ajpregu.00148.2012)

Rulicke T, Haenggli A, Rappold K, Moehrlen U \& Stallmach T 2006 No transuterine migration of fertilised ova after unilateral embryo transfer in mice. Reproduction, Fertility, and Development 18 885-891. (doi:10. 1071/RD06054)

Stevenson DK, Verter J, Fanaroff AA, Oh W, Ehrenkranz RA, Shankaran S, Donovan EF, Wright LL, Lemons JA, Tyson JE et al. 2000 Sex differences in outcomes of very low birthweight infants: the newborn male disadvantage. Archives of Disease in Childhood. Fetal and Neonatal Edition 83 F182-F185. (doi:10.1136/fn.83.3.F182)

Stoeckius M, Grun D \& Rajewsky N 2014 Paternal RNA contributions in the Caenorhabditis elegans zygote. EMBO Journal 33 1740-1750. (doi:10.15252/embj.201488117)

Struwe E, Berzl G, Schild R, Blessing H, Drexel L, Hauck B, Tzschoppe A, Weidinger M, Sachs M, Scheler C et al. 2010 Microarray analysis of placental tissue in intrauterine growth restriction. Clinical Endocrinology 72 241-247. (doi:10.1111/j.1365-2265.2009.03659.x)

Tang WX, Wang LK, Wang YQ, Zong ZJ, Gao ZX, Liu XS, Shen YJ, Shen YX \& Li YH 2014 Peroxisome proliferator-activated receptor- $\alpha$ activation protects against endoplasmic reticulum stress-induced HepG2 cell apoptosis. Molecular and Cellular Biochemistry 385 179-190. (doi:10.1007/s11010-013-1826-0)

Vatten LJ \& Skjaerven R 2004 Offspring sex and pregnancy outcome by length of gestation. Early Human Development 76 47-54. (doi:10.1016/ j.earlhumdev.2003.10.006)

Received 30 October 2014

First decision 20 November 2014

Revised manuscript received 17 February 2015

Accepted 27 February 2015 